\title{
Family Adjustments to War Separation and Reunion
}

\author{
By Elise Boulding
}

$\mathbf{M}$ UCH has been said but little is known about what happens to family life in wartime. In an effort to correct this situation, a study was undertaken in Iowa during the recent war and continued through part of the postwar period. ${ }^{1}$ Its purpose was to determine the effects of the absence of the husband-father on families with one or more children born prior to Pearl Harbor. Families with children were studied so that the impact of war-born separation and reunion on the most stable elements of the population could be examined. The 135 families chosen constituted a random sample drawn from the Iowa State Selective Service files. The wife in each family was the major informant, but whenever possible the husband was also interviewed.

\section{Basic Assumptions}

In setting out to study the effects of war separation on families with children, there was an implicit assumption that these families had developed a relatively stable, workable pattern for meeting the day-to-day needs of their family members. An analysis of the families in the study confirmed this, but the patterns varied considerably from family to family. The patterns could be ranged on a continuum with the absolutist types of matriarchy and patriarchy at one end, and the democratic pattern in which the children shared

1 Materials from this study form the basis of the recently published Families Under Stress by Reuben Hill (New York: Harper \& Brothers, 1950). Anyone who is interested in the statistical analysis of the families in the study is referred to this book, since there has been no attempt to incorporate figures into this article. with their parents, according to their capacity, in the processes of decision making and maintaining the home, at the other end. The adult-centered or two-headed family stood between the two extremes. The behavior within each family was relatively consistent, with the exception of the disorganized home. Here inconsistency became the pattern.

A second assumption was that the departure of the husband-father for the service and the eventual postwar reunion constituted crises for these families, defining crisis as a sudden alteration in a situation which makes the usual behavior patterns inadequate and at the same time demands an immediate response. The study was in fact intended to fit into the larger framework of the general study of families in crisis situations, and incorporated hypotheses from previous studies of families in the depression for further testing. ${ }^{2}$

It became apparent as individual stories unfolded that the event of induction of the man of the house into the armed forces did not necessarily constitute a crisis for every family, nor did his return after several years' absence. This fact crystallized sharply the realization gradually emerging from previous studies that an event, however cataclysmic, does not of itself produce a crisis. Instead, three variables determine whether a given event will produce

${ }^{2}$ Especially the following: Robert C. Angell, The Family Encounters the Depression, New York: Charles Scribner's Sons, 1936; Ruth Cavan and Katherine Ranck, The Family and the Depression, Chicago: University of Chicago Press, 1938; Mirra Komarovsky, The Unemployed Man and His Family, New York: Dryden Press, 1940. 
a crisis: (1) the hardships of the event, (2) the resources of the family to meet the event, and (3) the family's definition of the event. The error of confusing the event itself with the crisis is a common one, and leads to many easy but false generalizations concerning the effects of various kinds of catastrophe, such as unemployment, desertion, or bereavement, on families and individuals. Useful generalizations in this field can only be made in terms of the effect of catastrophic events on different types of family situations.

\section{Situational Analysis}

We use the word "situation" here in a technical sense, referring to the technique of situational analysis developed by Bossard. ${ }^{3}$ It was thought that an analysis of the preinduction situation of each family in the war-separation study in terms of the constructions made by Bossard might reveal typical configurations that would be predictive of certain types of adjustment, and this did indeed prove to be the case. Bossard defines a family situation as a unit of interacting stimuli organized around a specific focal point, and suggests that this situation can be studied from the point of view of the structure of the family, family processes, and the cultural content of the family life. This framework was found to be particularly useful for studying a family from the focal point of the potentially crisis-producing event of war separation. A further use of it in studying the impact on families of other catastrophic events should be fruitful.

\section{The Focal Event and Attendant HARDSHIPS}

The departure of the husband-father for the service was the focal event of

3 James H. S. Bossard and Eleanor S. Boll, Family Situations, Philadelphia: University of Pennsylvania Press, 1943. the family situations examined in our study. The reunion event was also examined in the 112 of the 135 families in which this took place before the study ended. In many cases, however, the family had not been reunited long enough to feel settled down, and were still in a kind of honeymoon euphoria, so sound evaluations of the reunion adjustment could not be made. The major part of the study was therefore centered on the separation crisis rather than the reunion crisis.

We have already said that whether the event of induction resulted in a crisis for a given family depended on the attendant hardships, the resources of the family to meet the situation, and the definition made by the family of the event. The second and third determinants lie within the family itself and will be discussed as the family structure and values are analyzed. The hardships of the event lie outside the family and are an attribute of the event itself. The hardships are thus a part of the content of the focal event.

The concept "hardship" is not easy to deal with in relation to family crises, because it has three aspects, and it is essential to deal with that aspect which is relevant to the problem at hand. As an over-all definition, we suggest the following: Hardships are those aspects of a crisis-precipitating event which demand a response in terms of resources which the event itself has temporarily paralyzed or made unavailable.

From the point of view of the sociologist, a hardship exists when a crisis event makes demands upon the family which cripple it in respect to the physical effectiveness or emotional health of the family. From the point of view of the community, a hardship exists whenever the traditional patterns of family living are seriously disrupted. Crisis situations tend to become stereotyped, and it is simply assumed that the ab- 
sence of the head of the house for military service creates certain hardships for any family. The family members, on the other hand, view the demands made by the crisis event in terms of their own family attitudes and patterns of interaction, their own resources, and their previous experiences with crises. Thus, demands which strain the resources of one family to the breaking point and cause great hardships may be met without effort by another family with a different set of resources; or demands which from the sociologist's point of view place too great a strain on the family's resources, may because of a particular set of values held by that family not be felt as hardships.

\section{SPECIFIC HaRdShips}

A brief survey of the hardships experienced by the families in our study from the point of view of the impartial observer indicates that no single hardship was common to the entire group of families. Even the elementary deprivation of doing without the husband, in all his varied functions of companion, decision maker, maintenance man, disciplinarian-guide-playmate for the children, and whatever other special functions he may have performed in each individual family, was not universally a hardship. In a few cases the husband was so abusive and irresponsible that his absence was a blessing. In other cases the wife had never been allowed to handle money or make decisions, and her enjoyment of her new freedom considerably modified her loneliness.

Inadequate finances was not nearly as prevalent or frightening a trouble as had been expected. Some families had larger incomes from allotment checks than they had ever had from civilian wages, and in most cases where the income was reduced the wife took pride in managing on the smaller sum. There was an occasional wife, however, who honestly could not make ends meet however hard she tried, and a sprinkling of women who preferred to play the part of the helpless female who couldn't manage money.

"Making the children mind" was a fairly common hardship, but by no means universal, because in a number of families the father took no responsibility as disciplinarian when he was home. In those cases this was no new job for the wife.

Prolonged maladjustment of the children was surprisingly scarce. In most families there was a period of initial upset, followed by a quick recovery. Where the maladjusted condition persisted, however, it usually entailed severe hardship for the wife, because the maladjustment manifested itself in difficult behavior problems. One little three-yearold regressed to creeping after a slight foot injury and did not become a biped again until "daddy" returned. Another child was literally overwhelmed by a pyramiding of catastrophes that began with the departure of her father for service, followed by a move to a new neighborhood, and culminated in the daily absence of her mother when the latter took a job to increase the income.

Living with in-laws was a hardship for some families. Reasons for moving in with the grandparents ranged from sheer loneliness on the one hand to hard financial necessity on the other. The more the move was dictated by necessity, the more it tended to be a hardship for the family involved.

Housing troubles directly precipitated by the separation, in terms of overcrowding, inadequate facilities, or sheer inability to find a place to live, were rare, but tough for those families which faced them.

Managing the home, like child rearing, was a hardship in those families in which the wife was new to most of the home maintenance responsibilities. In 
those cases where the husband was either irresponsible or absent from home much of the time for business reasons, the wife already carried full responsibility for managing the home, and felt no hardship in this particular respect. In other cases, grandparents or other relatives stepped in to help with the maintenance function, and in these cases, too, no hardship was present.

Illness of the wife, striking in the husband's absence, was almost inevitably a problem even when there were relatives to help with the children; one family with a tubercular wife and five children was in desperate straits by the time the husband returned.

Serious illness of a child was also a real hardship for a few families, particularly one in which a mother just back from the hospital with her sixth baby had all five of her other children ill in bed at once, two of them with pneumonia.

Having $a$ baby while the husband was away was the hardship that most clearly revealed the mettle of war wives. The going was rough, but nearly all of them came through with flying colors. These women already had from one to five children at home, and most of them seemed to suffer from additional family complications when the confinement period was at hand.

Taking a job to eke out the income was a hardship for some women, but others thoroughly enjoyed the challenge of this new experience. A great deal was demanded of these women; they had the same problems as all the other women of being both father and mother to the children and making decisions for the family, in addition to giving a major portion of each day to an entirely different and often exacting set of tasks. On the whole, the women who managed best had relatives who could help to care for the children, but several women who had children of school age managed to give them everything they needed and work too. Part-time jobs were the answer for a few.

\section{Meaning of Good Adjustment}

We have already indicated that generalizations regarding the effects of war on family life can be most useful when related to different types of family situations. We are here concerned with these effects in terms of the various kinds of adjustment made by different types of families. Before attempting to relate types of family situations to kinds of adjustment, it is necessary to examine what we mean by good adjustment. In general, good adjustment to crisis situations implies effective reorganization in the face of a changed situation. Good adjustment to wartime dismemberment may be of two opposite kinds, however: one includes the husband in the adjustment process and is predictive of a good reunion (open-ranks adjustment), and the other excludes the husband and is predictive of a poor reunion (closedranks adjustment).

The criteria for the two types of adjustment are the same except where the relationship of the husband to the family is concerned. The first criterion involves effectiveness of role redistribution: Is the family able to continue to do the same things for its remaining members that it has always done?

The second criterion involves the presence of emotional poise and a reasonably relaxed acceptance of a tensionproducing situation among the remaining family members, so that no one is hindered from playing his role by emotional upset. Adequate role redistribution is nullified if new roles are played at the cost of extreme repression of emotions or to the accompaniment of constant overt conflict. Under such circumstances the family is no longer fulfilling the same functions for its members, and is instead providing physical 
security at the expense of emotional security.

The third criterion requires that the absent husband continue to play some kind of role in the family that is mutually satisfactory and emotionally satisfying to husband, wife, and children. Only when all three criteria are met can the adjustment be considered good in terms of the family as a whole. The criteria for good reunion adjustment are the same as for good open-ranks separation adjustment. The pattern of role distribution need not be the same after the reunion as before the separation, so long as the pattern is mutually acceptable to all family members.

Each family in the study was classified according to quality of adjustment to separation and reunion. The classifications for separation adjustment were good rapid, good slow, fair, and poor. For the reunion adjustment the divisions were simply good and poor.

\section{Family Situations}

An analysis of the 112 families for which reunion data as well as separation data were available revealed relationships between certain types of structure, process and content and good adjustment to separation. Most of the factors which were important for good openranks adjustment to separation were also important for good reunion adjustment.

\section{Family structure}

In examining family structure, two aspects must be considered: the number of elements involved, and the patterned relationships between the elements of the structure. In addition to the conjugal unit, most of the families in the study had had in-laws or other relatives living in the same home with them at some time during their married life, and most of them had relatives in the immediate community if not in the home, during the separation. The presence of these relatives meant either a very helpful assistance in taking care of new burdens or a situation of augmented tension, bitterness, and secret scheming, depending on what the family relationships had been before separation. In the great preponderance of cases the presence of relatives in the home or in the immediate community made the adjustment to separation much easier. Children in the family, by contrast, appeared to have no such beneficent effect on family adjustment. Number of children related negatively (but not significantly) to adjustment to separation.

The structural relationships of the family have been thought of in terms of four different types of interaction patterns: (1) the patterns of decision making (which can also be thought of as dominance patterns), (2) the patterns of assuming responsibility for the maintenance of the home, (3) the patterns of assuming responsibility for the rearing of the children, and (4) the affectional configurations. Scales were constructed to capture each of these four facets of family living, and each family was scored according to its precrisis history. Several different dominance patterns resulted in good adjustment, ${ }^{4}$ but one significant factor was common to all the successful patterns, and that was the habit of mutual consultation. The absolutist patterns did not make for good adjustment, and the completely democratic pattern resulted in the most uniformly successful adjustment.

${ }^{4}$ The dominance patterns and the parallel family types are as follows: Absolute dominance-matriarchy, patriarchy. Struggle for absolute dominance-equalitarian adult-centered in conflict. Modified dominance-modified matriarchy, modified patriarchy. Voluntary co-operation, joint dominance by parents of children-equalitarian adult-centered. Voluntary co-operation of all members, no dominance--democratic. 
A mutually satisfactory and co-operative assumption of responsibility for maintenance of the home ${ }^{5}$ and a positive relationship on the part of both parents with the children ${ }^{\theta}$ were more closely related to good reunion adjustment than to good separation adjustment. These findings point up the paradox that while the most co-operative and interdependent families are the best equipped to deal with a separation situation, they at the same time find it particularly hard to do without the husband. In a temporary separation, then, a slight maladjustment may be the best adjustment.

Equality of affectional focus ${ }^{7}$ was important for good adjustment both to separation and to reunion, although special patterns of intimacy between parents and children also related to good adjustment provided that one parent was not consistently excluded from all the special intimacies. Marked cleavages in the line-up of affectional relationships, with father involved in one "clique" and mother in another, usually led to a closed-ranks type of adjustment to separation, followed by a poor reunion adjustment.

\section{Family process}

The attempt to analyze the nature of the family process, or the interaction between family members just before the crisis event, was hindered by the fact that the schedules were not set up to capture this particular item. Never-

5 Husband and wife were rated on a ninepoint scale on the degree to which they assumed a complementary responsibility for the maintenance of the home.

6 Husband and wife were rated on a ninepoint scale on the degree to which both parents assumed both the companion and the guidance functions for their children.

${ }^{7}$ A graphic representation of the affectional configuration of each family was constructed, revealing intensity and extent of reciprocity of affectional relationships between each pair of family members. theless, considerable pertinent material emerged. Ratings on marital adjustment ${ }^{8}$ were used as an index to the general health of family interaction before induction. Good marital adjustment proved to be more predictive of good adjustment to reunion than to separation, again suggesting that some degree of unadjustment to separation was possibly the best adjustment in terms of the future interaction of the reunited family group.

Successful experiences with previous crises were helpful in enabling the families to deal successfully with the separation and reunion crises, and most particularly affected the speed of adjustment; "experienced" families made a more rapid adjustment than "inexperienced" families. Facing up to the implications of the separation in advance and making all possible emotional and physical preparations also meant that good separation and reunion adjustments would follow.

Another indication of the nature of the preinduction family interaction was the definition the family made of the crisis event. In our discussion of hardships we indicated that the external realities of a situation and the family's view of that same situation do not necessarily correspond. The family's interpretation of the induction event depended upon past experiences and the patterns of family behavior that had been built up over the years, as well as on the hardships attendant on the event. However, it was fairly clear in this study that the extent to which families defined their situation as fraught with hardships depended to a considerable degree on how many hardships (objectively defined) they were faced with. For families faced with few hardships, the personal definition of the situation depended more directly on the family resources; but where there was a pile-up

${ }^{8}$ Subjective ratings made by the writer. 
of hardships, the families were very much aware of their hardships as troubles. Even the best-equipped family cannot take a sudden accumulation of difficulties without considerable strain.

\section{Cultural content}

No material was directly available on the cultural content of the family life. This concept was intended by Bossard to cover the family's attitudes to the surrounding culture. Which cultural values, for example, does a given family choose to incorporate into its own group life and to pass on to its children? In lieu of a direct answer to this question, the families were all rated on the degree to which they were integrated around a common value system and on the degree to which they adapted as a family unit to the demands of the society around them. Both these tests give an indication of how much the family values itself as a social unit. The concept of integration $^{9}$ does this by taking into consideration the number and strength of the common bonds uniting the family. The concept of adaptability considers the strength of the family "drive" for self-preservation.

It was found that adaptability was more important than integration for adjustment both to separation and to reunion, and that both adaptability and integration were more predictive of type of adjustment to reunion than to separation. This raises the question of the relative importance of integration and adaptability for family survival. While both are essential, it is true that the number of common interests binding family members together today is much smaller than it was even a generation ago, and a much smaller area of life is shared by the entire family group. However, the family members so prize the

\footnotetext{
- Concepts developed by Angell, op. cit. note 2 supra.
}

common bonds that do exist, chiefly affectional ones, that they are willing to pool the individual resources with which they separately meet many of the community demands, in order to develop techniques of family adjustment whenever the family unit is threatened from within or without.

The apparent shift in emphasis from integration to adaptability represents an attempt to hold some family values fast in the face of a rapidly changing society which makes increasingly diversified demands on the individual and increasingly fewer demands on the family as such. What is needed here is a redefinition of integration which lays more emphasis on the quality of the common bonds than on the number of them.

\section{Configurations}

Are the various factors that have been discussed in relation to good adjustment to separation and reunion simply a series of isolated factors, or do they form typical configurations, to be found repeatedly in families having made a good adjustment? In order to answer this question a scale of family adequacy was constructed, consisting of all the items that taken individually were definitely predictive of good adjustment to separation and reunion. ${ }^{10}$ All the families in the study were rated on this scale. The hypothesis that a certain typical cluster of traits would be found in those families making a good adjustment was

10 The following items were included in the scale: moderate to high integration; moderate to high adaptability; good adjustment to previous crises; any of the following patterns of dominance: equalitarian adult-centered, democratic, modified patriarchy, and modified matriarchy; highest and next highest ratings on assumption of responsibility for maintenance of home and guidance of children; equality of participation in affectional life. Families were scored one point for each of these evidences of family adequacy, total scores ranging from 0 to 7 . 
at least partially confirmed by the fact that these "good adjustment" families made high adequacy scores.

\section{Modes of Adjustment}

We turn now from our study of preseparation family situations to an examination of the processes of adjustment undergone by these same families. Koos ${ }^{11}$ has suggested that the course of adjustment to crises can be separated into five stages: (1) precrisis situation, (2) anticipation of crisis, (3) immediate reactions of disorganization to crisis event, (4) process of reorganization and recovery, and (5) level of final readjustment. The precrisis situation and anticipatory reactions to the crisis have already been discussed in the situational analysis. We will now examine steps 3,4 , and 5 to see what modes of adjustment work best in terms of successful reunions.

Families that made ultimately good adjustments had immediate reactions to the separation that ranged all the way from feelings of excitement and unreality to a relative calm; but extreme reactions of emotional upset and numbness did not augur well for the separation adjustment. Indifference presaged a good closed-ranks adjustment to separation, and a poor reunion.

Families that made a good final adjustment found the recovery period difficult but not impossible, were generally too busy to mope, and had some help from friends and relatives. The more democratically organized of these families were a little slower in making their readjustment than the less democratic ones; greater interdependence may have necessitated a greater emotional readjustment. The families missed their men very much. The initial disorganizing effects of the husband's departure had, however, worn off in all the cases

${ }^{11}$ E. L. Koos, Families in Trouble, New York: King's Crown Press, 1946. except those that never did make a satisfactory adjustment to separation.

The best level of final readjustment was reached by those families which partially closed ranks and continued an affectional and companionate relationship with the husband through letters. Immediate family problems were settled without his advice. Good adjustments were also made when the husband continued more completely his old role in the home, sharing the decision-making. This was true only when the family was not absolutely dependent on his decisions, however, but shared the decision process with him in order to make him feel as much a part of the family as possible. Good adjustments were also made by families which had grandparents who could step in and take over some of the husband's responsibilities in order to relieve the mother of her double load. It was relatively rare, however, for the mother to take full-time employment outside the home.

\section{Reunion Adjustments}

The types of reorganization just discussed all made good reunion adjustments possible, too. The wife who took over the husband's role completely and dreaded his return as an infringement on her freedom made a good separation adjustment but a poor reunion adjustment. The families which made a poor adjustment to separation did not close ranks at all, but persisted in a state of unorganized dismemberment, throwing on the absent husband the full burden of decision-making for the family. ${ }^{12}$

The reunion adjustment, as might be expected, followed a different course from the separation adjustment. Instead of initial distress and disorganiza-

12 This is in contrast to the well-adjusted families which desired the husband to continue to share in the family council in order not to destroy the feeling of belongingness. 
tion, the immediate reaction was one of intense joy. The recovery period was marked by an atmosphere of honeymoon euphoria which sometimes considerably retarded the real recovery process. As the honeymoon glow died down, the families in general returned more or less to their prewar patterns of family behavior, good or bad.

There were also some real differences in family behavior as a result of the separation, however. An increased appreciation of the values of family life on the part of both husband and wife was evident in a number of families. In these cases a more co-operative relationship was established which might well become more permanent where there were no serious conflicts in the prewar period. In cases where the wife had enjoyed exercising new managerial skills in the family and wished to continue to do so, if there was a basically good relationship in the home, the returned husband frequently recognized and appreciated her previously hidden abilities. As a result, a somewhat new family division of labor was often worked out.

External obstacles to readjustment were numerous-lack of adequate housing, difficulty in finding work, inadequate finances, and other problems. Most wives reported that the husbands were tense, nervous, "hard to get along with" in the first few weeks. Particularly was it hard for the husbands to get used to the children. As they worked through these difficulties, the families were reaping what they had sown in the prewar years. Habits of talking things over, a united attitude toward the values of family life, a strong mutual companionship-these and other factors discussed in the situational analysis helped the family to take the reunion problems in its stride. On the other hand, seeds of dissension sown in the prewar years yielded a plentiful harvest of quarrels and mutual distrust, sometimes ending in separation for the less well equipped families.

Elise Boulding, M.S., Ann Arbor, Michigan, is a graduate student at the University of Michigan. She was research assistant to Reuben Hill at Iowa State College while the study described in this article was in process. 